\title{
Gabapentin vs. Pregabalin for the Treatment of Neuropathic Pain in Patients with Spinal Cord Injury: A Crossover Study
}

\author{
Bilge YILMAZ, Evren YAŞAR, Özlem KÖROĞLU OMAÇ, Ahmet Salim GÖKTEPE, Arif Kenan TAN \\ Department of Physical Medicine and Rehabilitation, Gülhane Military Medical Academy, Rehabilitation Center, Ankara, Turkey
}

\begin{abstract}
Objective: Neuropathic pain is a frequent complication of spinal cord injury. Almost $70 \%$ of patients with spinal cord injury $(\mathrm{SCl})$ experience pain, and nearly one-third of these patients describe their pain as severe. Gabapentin and pregabalin are considered as first-line treatment for post-SCI neuropathic pain. However, there is no study comparing the effects of gabapentin and pregabalin in the management of neuropathic pain in patients with $\mathrm{SCl}$. In this prospective, randomized, crossover clinical trial, we aimed to compare the efficacy of gabapentin and pregabalin in the treatment of neuropathic pain associated with SCl.

Material and Methods: Thirty patients with spinal cord injury experiencing neuropathic pain were recruited for the study. Patients took medications for 8 weeks. After a 2-week washout period, medications were switched in a crossover design. The outcome measures for this study were visual analogue scale (VAS) for pain, VAS for sleep, Short Form Beck Depression Inventory, and the pain disability index.

Results: Twenty-one patients completed the study. Seven patients who did not want to change their medication while they were using the first drug (4 patients were using gabapentin and 3 patients were using pregabalin) and 2 patients who experienced dizziness and nausea (both were in the pregabalin group) were dropped off. There was no difference between both drugs in terms of their efficacy for pain, anxiety, and sleep ( $p<0.05$ ). Conclusion: There was no statistically significant difference between gabapentin and pregabalin in terms of study parameters for the treatment of neuropathic pain in patients with $\mathrm{SCl}$.

Keywords: Spinal cord injury, neuropathic pain, gabapentin, pregabalin
\end{abstract}

\section{Introduction}

Neuropathic pain is a frequent complication of spinal cord injury (SCI). Almost $70 \%$ of patients with $\mathrm{SCl}$ experience pain, and nearly one-third of those patients describe their pain as severe (1). Therefore, pain interferes with SCI patients' daily activities, social participation, and quality of life (2). The majority of patients complaining of chronic pain report pain onset within the first 6 months of their injury, irrespective of the type of pain
(3). For neuropathic pain observed after SCl, antiepileptics and antidepressant drugs are reported to be commonly used (4).

Mechanisms of neuropathic pain following $\mathrm{SCl}$ are not totally clear. However, there are many anatomical, neurochemical, excitotoxic, and inflammatory alterations from peripheral sites to the brain that could lead to a change in spinal neuron function and then to pain (5). Because elimination of the cause of pain may not generally be possible, the focus of treatment then becomes symptomatic relief or helping the patient to manage pain. 
There are a large number of treatments that are used for symptomatic relief, often with little evidence of efficacy. Even when controlled clinical trials have been performed, satisfactory relief (as defined by a 50\% reduction in pain) is at best obtained in about one-third of patients (6).

Gabapentinoids, which are now considered to be first-line treatment for post-SCI neuropathic pain, mimic the neurotransmitter GABA and show indirect interaction with the GABA receptor. Interaction with voltage gated $\mathrm{N}$-type calcium ion channels at the $\alpha_{2} \delta$ subunit and also indirect interaction with the NMDA receptor could increase the activity of inhibitory neurons, causing a decrease in the transmission of nociceptive signals $(4,7)$.

Ahn et al. (8) conducted a before-and-after trial of SCl patients with pain, in which they found that gabapentin was effective in decreasing neuropathic pain refractory to conventional analgesics. Siddall et al. (9) reported that patients in the treatment group receiving 150 to $600 \mathrm{mg}$ daily of pregabalin experienced a significantly greater improvement in pain and sleep than those in the control group. Vranken et al. (10) found that subjects in the pregabalin treatment group reported a significant decrease in pain and improvements in visual analogue scale (VAS) and SF-36. Levendoglu et al. (11) conducted a crossover study involving 20 subjects with neuropathic pain for more than 6 months, in which they found that gabapentin was more effective than placebo in reducing neuropathic pain. To et al. (12) studied the impact of gabapentin in SCl patients with neuropathic pain and reported a significant decrease in pain. Rintala et al. (13) compared the effects of gabapentin, amitriptyline, and an active control (diphenhydramine) on pain intensity after $\mathrm{SCl}$ in patients with neuropathic pain. Gabapentin, when compared with amitriptyline or diphenhydramine, was not more effective in reducing pain intensity.

To the best of our knowledge, there is no study comparing the effects of gabapentin and pregabalin in the management of neuropathic pain in patients with $\mathrm{SCl}$. The aim of this study was to compare the effectiveness of gabapentin and pregabalin in $\mathrm{SCl}$ patients with neuropathic pain.

\section{Material and Methods}

The study was designed as a prospective, crossover, randomized clinical trial. The study protocol was approved by the local ethics committee, and written informed consent was provided by each patient.

The 18-week study period included 8 weeks for gabapentin or pregabalin use and a 2-week washout period between the use of two medications. After the washout period, drugs were switched in a crossover design.

Inclusion criteria for this study were as follows: $\mathrm{SCl}$ patients with pain below the level of injury in areas without normal sensation (14), age between 14 and 75 years, and a Self-Administered Leeds Assessment of Neuropathic Symptoms and Signs (LANNS) score above 12. Exclusion criteria were as follows: concomitant brain injury, cognitive impairment, seizure disorder, the use of antiepileptics and antidepressants, and hypersensitivity history to gabapentin and pregabalin. The use of other analgesic medications was stopped at least 15 days before the study, and patients were informed not to use other analgesics during the study. Laboratory testing was performed at weekly intervals during the study.

Patients completed the LANNS Scale, pain VAS, sleep VAS, Short Form Beck Depression Inventory (Harcourt Brace \& Co., San Antonio, TX), and the pain disability index before and after each treatment period $(15,16)$.

The LANNS Scale is a 7-item self-report scale that was developed to identify pain of predominantly neuropathic origin (17). A score exceeding 12 on the LANNS Scale, representing neuropathic pain, was required for inclusion in the study. Turkish version of S-LANNS is a reliable and valid differential diagnostic measure of neuropathic pain (18). The VAS has proven to be a reliable and a valid measure of pain intensity and unpleasantness (19).

The baseline pain level and the effect of pain on sleep was recorded once a day for the last week using a 10-point VAS scale before initiating medication. Additionally, subjective intensity and frequency of pain, disability due to pain, and quality of sleep were assessed using 10-point scales. During the study period (18 weeks), patients were asked to document pain levels on the VAS and the effect of pain on sleep every night in their daily diaries, in which the morning and afternoon pain levels were recorded on the same day, as well as the previous day's nighttime pain level was documented. The evaluation of these scores was conducted at baseline times (weeks $0,8,10$, and 18); Short Form Beck Depression Inventory and the pain disability index were also documented at baseline times (weeks $0,8,10$, and 18).

Patients were initially randomized into a gabapentin treatment group (group A) or a pregabalin treatment group (group B). During the first 2 weeks of the use of each medicine, patients received gradually titrated dosages. Gabapentin was administered orally 3 times a day; however, pregabalin was administered 2 times a day. Before increasing the dose at each interval, the subject was observed by a blinded physician to document any side effects. If no significant side effects were noted, the dose was increased. Adverse effects of medicines were monitored and recorded. All patients' dosages were titrated to tolerability up to $1800 \mathrm{mg} /$ day for gabapentin and $300 \mathrm{mg} /$ day for pregabalin during 2 weeks, regardless of any efficacy achieved at lower dosages.

\section{Statistical Analysis}

StatsDirect Statistical software was used for crossover analysis of pain and sleep VAS, Beck Depression assessment, and pain disability index scores within and between the groups. The significance level was set at $p<0.05$.

\section{Results}

Thirty patients with spinal cord injury experiencing neuropathic pain were recruited for the study. Twenty-five of them 
Table 1. Raw data obtained from both groups

\begin{tabular}{|c|c|c|c|c|c|c|c|c|}
\hline & \multicolumn{4}{|c|}{ First period } & \multicolumn{4}{|c|}{ Second period } \\
\hline & \multicolumn{2}{|c|}{ Pregabalin group } & \multicolumn{2}{|c|}{ Gabapentin group } & \multicolumn{2}{|c|}{ Pregabalin group } & \multicolumn{2}{|c|}{ Gabapentin group } \\
\hline & Beginning & End & Beginning & End & Beginning & End & Beginning & End \\
\hline Sleep VAS & $4.92 \pm 3.94$ & $3.23 \pm 4.13$ & $5.14 \pm 3.84$ & $1.72 \pm 2.79$ & $5.00 \pm 4.5$ & $0.81 \pm 1.64$ & $5.40 \pm 5.07$ & $1.25 \pm 2.5$ \\
\hline BDI & $17.42 \pm 10.94$ & $14.23 \pm 11.79$ & $10.64 \pm 5.31$ & $10.5 \pm 5.0$ & $12.12 \pm 3.64$ & $10.85 \pm 3.80$ & $13.80 \pm 13.31$ & $6.5 \pm 2.64$ \\
\hline
\end{tabular}

VAS: visual analog scale; PDI: pain disability index; BDI: Beck depression inventory

Table 2. Crossover analysis of the results

\begin{tabular}{|c|c|c|c|c|c|c|c|c|}
\hline & \multicolumn{2}{|c|}{$\begin{array}{l}\text { Test for relative } \\
\text { effectiveness of } 2 \text { drugs }\end{array}$} & \multicolumn{2}{|c|}{$\begin{array}{l}\text { Test for treatment } \\
\text { effect }\end{array}$} & \multicolumn{2}{|c|}{$\begin{array}{l}\text { Test for period } \\
\text { effect }\end{array}$} & \multicolumn{2}{|c|}{$\begin{array}{l}\text { Test for treatment-period } \\
\text { interaction }\end{array}$} \\
\hline & $t$ & p & $t$ & $p$ & $t$ & $p$ & $t$ & $p$ \\
\hline PDI & -0.69 & 0.50 & -0.70 & 0.49 & -1.38 & 0.18 & -0.74 & 0.47 \\
\hline $\mathrm{BDI}$ & 0.61 & 0.55 & 0.61 & 0.55 & -1.04 & 0.31 & -1.63 & 0.12 \\
\hline
\end{tabular}

PDI: pain disability index; $\mathrm{BDI}$ : Beck depression inventory

were male (83.3\%), and 5 of them were female $(16.7 \%)$, with age ranging from 14 to 63 years (mean age, $32.93 \pm 11.87$ ). The mean time since injury was $31.48 \pm 61.08$ months (range, 1-276 months). The mean motor score was $52 \pm 19.52$, and the mean sensory score was $142.80 \pm 49.35$.

Seven patients who did not want to change their medication while they were using the first drug (4 patients were using gabapentin and 3 patients were using pregabalin) and 2 patients who experienced the side effects of dizziness and nausea (both were in the pregabalin group) were dropped off. Finally, 21 patients completed the study (female: male, $2: 19$ ). The mean age was $33.7 \pm 11.8$ years (range, 20-63 years). The mean time since injury was $30.3 \pm 65.9$ months (range, 1-276 months).

The raw data of evaluations are presented in Table 1. Crossover analysis of the results revealed that there was no difference between both drugs in terms of all assessments of neuropathic pain (pain and sleep VAS, Beck depression inventory, and the pain disability index) outcome measures ( $p>0.05$ ) (Table 2).

\section{Discussion}

The results of this study revealed that pregabalin was as effective as gabapentin in the treatment of neuropathic pain in patients with $\mathrm{SCl}$. We also found that both gabapentin and pregabalin were effective in improving sleep and anxiety. This may reflect an improvement in daily functioning and ability to participate in life activities, which may be interpreted as an improvement in quality of life. There was no statistically significant difference between these 2 agents in terms of pain, sleep, anxiety, daily functioning, and ability to participate in life activities.

Neuropathic pain is a common problem after SCl. Many studies have provided evidence that $\mathrm{SCl}$-related pain leads to decreased function and quality of life (1). However, the present literature demonstrates a substantial need for comparative studies of pharmacologic therapies for neuropathic pain (20).

There is strong evidence supporting the use of gabapentin and pregabalin in the treatment of pain after $\mathrm{SCl}$, particularly central or neuropathic pain $(4)$. Gabapentin $(8,11,12)$ and pregabalin $(9,10)$ have both been shown to be effective in reducing such pain after SCl. They have been shown to be first-line therapy with tricyclic antidepressants in the most recent literature $(19,21)$.

In a crossover study (11) involving 20 subjects with neuropathic pain for more than 6 months, it was found that gabapentin was more effective $(p<0.05)$ than placebo in reducing neuropathic pain. Pain relief was observed with gabapentin use from the beginning of the study; however, statistically significant pain relief started from the second week, and this corresponded to a dose of $1800 \mathrm{mg} /$ day. Therefore, we titrated the dosages up to $1800 \mathrm{mg}$ /day for gabapentin as an optimum dosage in our study. A randomized trial of pregabalin in patients with neuropathic pain due to $\mathrm{SCl}$ showed strong evidence that 150-600 $\mathrm{mg}$ /day pregabalin was effective in reducing duration-adjusted average change in pain compared with baseline (22). In current study, we observed significant pain relief with $300 \mathrm{mg} /$ day pregabalin. 
Adverse effects of gabapentin and pregabalin have been reported to be minor and well tolerated, consisting primarily of somnolence, dizziness, weakness, edema, vertigo, and headache. These drugs also have the benefit of limited interactions with other medications and the lack of organ toxicity (11). In our study, 2 patients in the pregabalin group experienced side effects. These side effects led to discontinuation of treatment (dizziness and nausea) and were similar to the literature $(4,9)$.

One important issue to be considered during crossover analysis is carryover or residual effects. Carryover effects occur when the effect of treatment given in the first period persists into the second period and changes the effect of the second treatment. The absence of a statistically significant period effect or treatment-period interaction in our study revealed that there was no carryover effect.

The limitations of our study were a small sample size and the lack of quality of life assessment. In this study, the results revealed that the efficacy of pregabalin for pain was superior to the efficacy of gabapentin, although it was not statistically significant $(p=0.06)$. A larger sample size may clarify this potential trend toward significance. Further studies should compare the effects of gabapentinoids on daily functioning and quality of life in patients with $\mathrm{SCl}$.

\section{Conclusion}

According to the results of our study, both gabapentin and pregabalin can be added to the list of first-line medications for the treatment of neuropathic pain in patients with $\mathrm{SCl}$.

Ethics Committee Approval: Ethics committee approval was received for this study from the ethics committee of Gülhane Military Medical Academy.

Informed Consent: Written informed consent was obtained from patients who participated in this study.

Author contributions: Concept - B.Y.; Design - B.Y.,E.Y.; Supervision - A.S.G., A.K.T.; Resource - E.Y., Ö.K.O.; Materials - E.Y., Ö.K.O.; Data Collection and/or Processing -B.Y., E.Y., Ö.K.O.; Analysis and/or Interpretation - B.Y., A.S.G.; Literature Search - B.Y., Ö.K.O.; Writing - B.Y., E.Y., A.S.G.; Critical Reviews - E.Y., A.K.T.

Conflict of Interest: No conflict of interest was declared by the authors.

Financial Disclosure: The authors declared that this study has received no financial support.

\section{References}

1. Stormer S, Gerner HJ, Gruninger W, Metzmacher K, Föllinger S, Wienke C, et al. Chronic pain/ dysaesthesiae in spinal cord injury patients: results of a multicentre study. Spinal Cord 1997;35:446-55. [CrossRef]

2. Donnelly C, Eng JJ. Pain following spinal cord injury: the impac on community reintegration. Spinal Cord 2005;43:278-82. [CrossRef]
3. Siddall PJ, McClelland JM, Rutkowski SB, Cousins MJ. A longitudinal study of the prevalence and characteristics of pain in the first 5 years following spinal cord injury. Pain 2003;103:249-57. [CrossRef]

4. Teasell RW, Mehta S, Aubut JA, Foulon B, Wolfe DL, Hsieh JT, et al; Spinal Cord Injury Rehabilitation Evidence Research Team. A systematic review of pharmacologic treatments of pain after spinal cord injury. Arch Phys Med Rehabil 2010;91:816-31. [CrossRef]

5. D'Angelo R, Morreale A, Donadio V, Boriani S, Maraldi N, Plazzi G, et al. Neuropathic pain following spinal cord injury: what we know about mechanisms,assessment and management. Eur Rev Med Pharmacol Sci 2013;17:3257-61.

6. Finnerup NB, Johannesen IL, Sindrup SH, Bach FW, Jensen TS. Pain and dysesthesia in patients with spinal cord injury: A postal survey. Spinal Cord 2001;39:256-62. [CrossRef]

7. Hendrich J, Van Minh AT, Heblich F, Nieto-Rostro M, Watschinger $\mathrm{K}$, Striessnig J, et al. Pharmacological disruption of calcium channel trafficking by the alpha2delta ligand gabapentin. Proc Natl Acad Sci USA 2008;105:3628-33. [CrossRef]

8. Ahn SH, Park HW, Lee BS, Moon HW, Jang SH, Sakong J, et al. Gabapentin effect on neuropathic pain compared among patients with spinal cord injury and different durations of symptoms. Spine 2003;28:341-6. [CrossRef]

9. Siddall PJ, Cousins M], Otte A, Griesing T, Chambers R, Murphy TK. Pregabalin in central neuropathic pain associated with spinal cord injury: a placebo-controlled trial. Neurology 2006;67:1792-800. [CrossRef]

10. Vranken JH, Dijkgraaf MG, Kruis MR, Van der Vegt MH, Hollmann MW, Heesen M. Pregabalin in patients with central neuropathic pain: a randomized, double-blind, placebo-controlled trial of a flexible-dose regimen. Pain 2008;136:150-7. [CrossRef]

11. Levendoglu F, Ogun CO, Ozerbil O, Ogun TC, Ugurlu H. Gabapentin is a first line drug for the treatment of neuropathic pain in spinal cord injury. Spine 2004;29:743-51. [CrossRef]

12. To TP, Lim TC, Hill ST, Frauman AG, Cooper N, Kirsa SW, et al. Gabapentin for neuropathic pain following spinal cord injury. Spinal Cord 2002;40:282-5. [CrossRef]

13. Rintala DH, Holmes SA, Courtade D, Fiess RN, Tastard LV, Loubser PG. Comparison of the effectiveness of amitriptyline and gabapentin on chronic neuropathic pain in persons with spinal cord injury. Arch Phys Med Rehabil 2007;88:1547-60. [CrossRef]

14. Cardenas DD, Turner JA, Warms CA, Marshall HM. Classification of chronic pain associated with spinal cord injuries. Arch Phys Med Rehabil 2002;83:1708-14. [CrossRef]

15. Rejas ], Riberab MV, Ruiz M, Masrramon X. Psychometric properties of the MOS (Medical Outcomes Study) Sleep Scale in patients with neuropathic pain. Eur J Pain 2007;11:329-40. [CrossRef]

16. Tait RC, Pollard CA, Margolis RB, Duckro PN, Krause SJ. The Pain Disability Index: psychometric and validity data. Arch Phys Med Rehabil 1987;68:438-41

17. Bennett M. The LANSS Pain Scale: the Leeds assessment of neuropathic symptoms and signs. Pain 2001;92:147-57. [CrossRef]

18. Koc R, Erdemoglu AK. Validity and reliability of the Turkish Selfadministered Leeds Assessment of Neuropathic Symptoms and Signs (S-LANSS) questionnaire. Pain Med 2010;11:1107-14. [CrossRef] 
19. Watson CPN. The treatment of neuropathic pain: antidepressants and opioids. Clin J Pain 2000;16:49-55. [CrossRef]

20. Snedecor SJ, Sudharshan L, Cappelleri JC, Sadosky A, Desai P, Jalundhwala YJ, et al. Systematic review and comparison of pharmacologic therapies for neuropathic pain associated with spinal cord injury. J Pain Res 2013;6:539-47. [CrossRef]
21. Baron R, Binder A, Wasner G. Neuropathic pain: diagnosis, pathophysiological mechanisms, and treatment. Lancet Neurol 2010;9:80719. [CrossRef]

22. Cardenas DD, Nieshoff EC, Suda K, Goto S, Sanin L, Kaneko T, et al. $A$ randomized trial of pregabalin in patients with neuropathic pain due to spinal cord injury. Neurology 2013;80:533-9. [CrossRef] 